\title{
Solar irradiation and PV module temperature dispersion at a large-scale PV plant
}

\author{
Miguel García ，Luis Marroyo , Eduardo Lorenzo , Javier Marcos and Miguel Pérez
}

\begin{abstract}
When evaluating the performance of a photovoltaic (PV) system, it is extremely important to correctly measure the plant operating conditions: incident irradiation and cell temperature. At large-size PV plants, the possible dispersion of the plant operating conditions may affect the representativeness of the values measured at one single point. The available literature contains many observations on irradiance dispersion (typically associated to high temporal resolution experiments) and its effects on the PV power output (unexpected power transients, power fluctuations, etc.). However no studies have been made on the long-term energy-related effects of geographic dispersion of solar irradiation, which could affect, for example, to the uncertainty in determining energy performance indexes like PR. This paper analyses the geographical dispersion in the PV operating conditions observed at low temporal resolutions (day, month and year) at two PV plants located, respectively, in the south of Portugal and the north of Spain. It shows that daily irradiation deviations are significantly higher than is commonly supposed. Furthermore, once the measurement points are a certain distance apart (a few hundred metres), the deviations in irradiation appear to be independent of distance. This could help to determine how many irradiance sensors to install in order to reduce uncertainty. Daily mean temperature differences between different points at a large-scale PV plant range from 1 to $7 \mathrm{~K}$ and are not related to the distance between measurement points. Copyright $\odot 2014$ John Wiley \& Sons, Ltd.
\end{abstract}

KEYWORDS

dispersion; irradiation; temperature; large PV plants

\section{INTRODUCTION}

The relationship between observed operating conditions, that is, in-plane irradiation and photovoltaic (PV) module temperature, and PV energy production are on the basis of several PV engineering practices. For example, energy production guaranties use to be established in terms of the Performance Ratio, which is simply an expression of the energy/irradiation ratio [1] and is sometimes corrected in temperature [2]. Obviously, irradiance and module temperature are measured just at one single point (at the corresponding sensor location), whilst PV power output responds to the operating conditions in the large area occupied by the entire PV generator. At large-size PV plants, the spatial dispersion of the plant operating conditions may affect the representativeness of the values measured at one single point and, therefore, the results of the performance evaluation.

Some irradiance dispersion observations are found at the literature typically associated to high temporal resolution experiments [3]. One-second records at Munich, initially aimed at observing the effect of cloud irradiance enhancement by moving cumulus [4], give raise to subsequent work on spatial irradiance characteristics, after realising that for systems of significant spatial expanse, part of the system will operate under irradiance enhancement whilst others will be simultaneously clouded [5]. A method for generating high densities grid of irradiance values, based on first deriving the cloud velocity vector from irradiance data sets corresponding to just few sensors, has been developed [6], and its predictions contrasted with observations at the Kalaeloa Airport Oahu Island in 
Hawaii, equipped with 17 global horizontal irradiance sensors distributed over an area of approximately $1 \mathrm{~km}$ by $1 \mathrm{~km}$ and making 1-s measurements at exactly the same time, to observe how clouds move through a large PV system $[7,8]$. Simultaneous 1 -s irradiance values have also been recorded at a network of six PV plants distributed over an area of approximately $1000 \mathrm{~km}^{2}$ [8]. All this work based on high temporal resolution data has already given interesting results, essentially related with PV power (not energy) characteristics: transient PV output power up 30\% higher than at Standard Test Conditions have been reported [5,9], smoothing of PV power fluctuations by geographical dispersion has been modelled [10] and so on and still offer a large potential to increase the accuracy of simulations of PV power plants, to compare different interconnection layouts, and different maximum power point tracking, or even to attempt to simulate the combined effect of PV power plants in the low-voltage distribution grid [11]. However, today PV energy (not power) related results are restricted to note that irradiance enhancement yearly energy content is below $2 \%$ [5].

This paper deals with solar radiation and temperature dispersion observed at low temporal resolutions: 1 day, 1 month and 1 year. Differences on long-term irradiation values are likely caused not only by moving cumulus but also by other cloud phenomena, such as static lenticulars clouds shading just a limited zone inside the PV field, convective clouds form evolution, etc. Observations were taken over the course of an entire year at two PV plants, one with nine measurement points, at distances of 466-2716 m apart, whilst the other has just two measurement points, at a distance of $30 \mathrm{~m}$ apart. Measurements have been recorded at 10 -min intervals and allow observing high transient irradiance differences (Figure 1). Nevertheless, our analysis here focuses on long-term energy consequences, in terms of uncertainty when determining energy performance indexes. This is of relevance for engineering practices: PV plant state-of-health evaluations, often based on daily energy production analysis; application of energy production guarantees, often established in monthly or yearly terms and so on. As far as we know, the literature does not contain references to these energyrelated effects of solar radiation geographic dispersion. A particularly outstanding result is that daily irradiation deviations between $400 \mathrm{~m}$ separated points are significantly larger than is commonly supposed.

\section{EXPERIMENTAL SETUP}

The PV plant at Amareleja (Portugal) is an example of the ever increasing scale of the PV plants installed around the world over the last few years. With 2520 azimuth solar trackers spread over an area of 250 hectares, the plant has an STC power rating of $45.6 \mathrm{MWp}$. Nine calibrated modules spread across the entire surface area of the plant (Figure 2) are used to measure the radiation on the tracker plane and the temperature of the modules. These reference modules are identical to the ones incorporated in the PV generators, and are mounted at the top of the trackers to ensure that they are not affected by the eventual shadow cast by the adjoining trackers (Figure 2). The ground in the PV plant is fairly flat. It is possible, therefore, to consider that there is no significant local variation in the diffuse and ground reflected irradiance components on the system at a sunny instant.

Table I shows the distance in metres between the modules. The nearest modules are $466 \mathrm{~m}$ apart, whilst the furthest distance is $2716 \mathrm{~m}$.

Each reference PV module is divided into two, taking advantage of the accessible points at the PV module junction box. One part is kept short-circuited and used as irradiance sensor, whilst the other is kept as an open circuit and used as temperature sensor [12]. Conversion from these current $\left(I_{\mathrm{sc}}\right)$ and voltage $\left(V_{\mathrm{oc}}\right)$ values to irradiance and temperature ones are in accordance with IEC 60891 [13]. The calibration values of all the reference modules, that is, the irradiance/short-circuit relation, were corrected on a daily basis, so that the irradiance values given by all the reference modules at a sunny instant around midday coincided. This correction was very slight along the whole year, typically below $1 \%$, but still of interest in order to

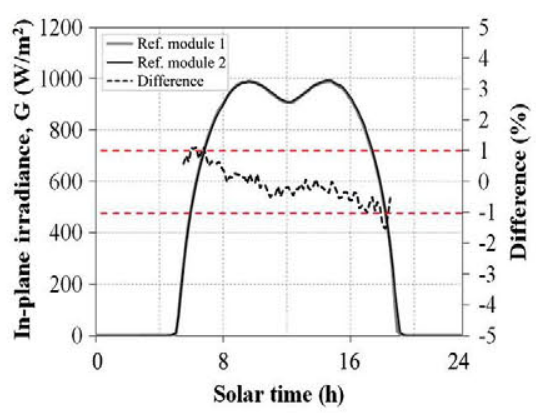

a)

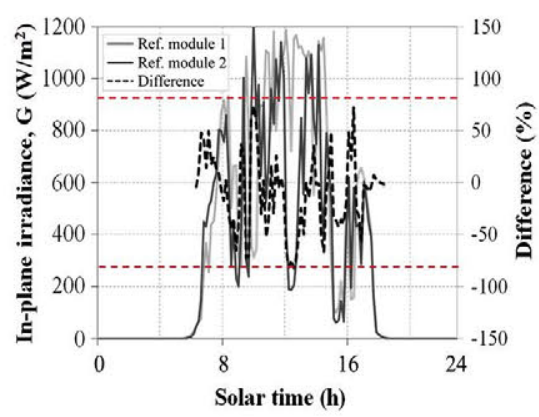

b)

Figure 1. One vertical-axis tracking irradiance measured with two calibrated modules $750 \mathrm{~m}$ apart. The dotted line represents the difference in measurements as $a \%$ of the maximum irradiance measured: (a) clear day, (b) partially cloudy day. Note that the appearance of two maximum in the clear day irradiance profile is typical for one vertical-axis tracking inclined surfaces, during summer months (normal incidence occurs before and after the noon). 

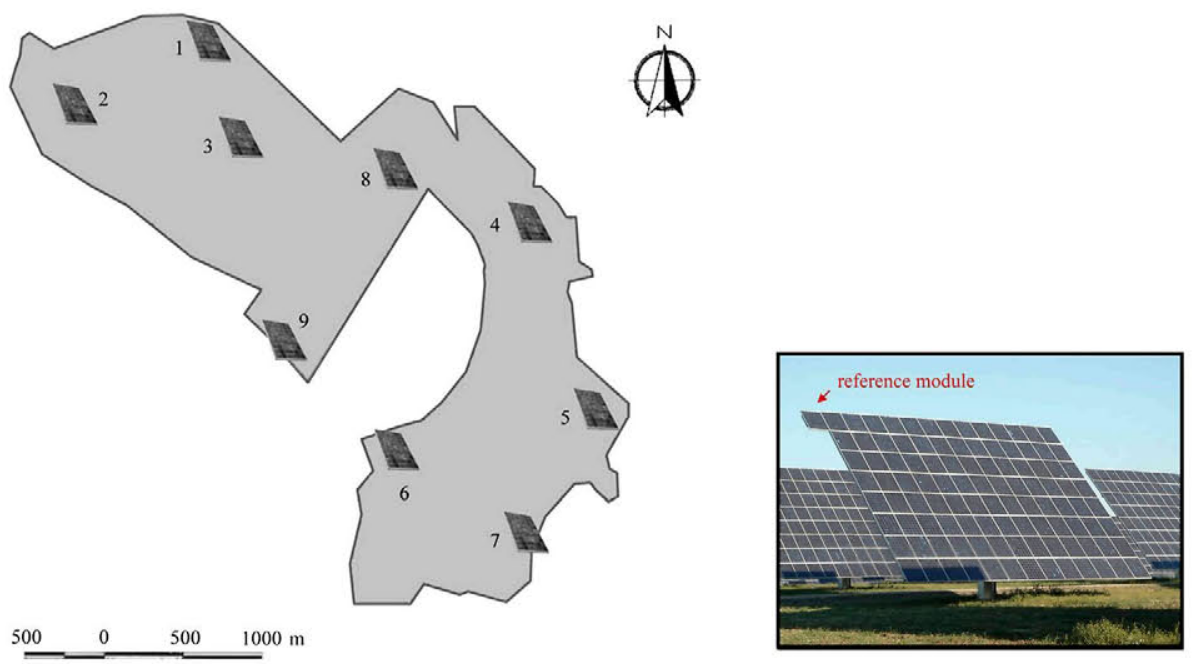

Figure 2. Layout of the reference modules over the photovoltaic plant area and photo of the reference module mounted on the top of one of the trackers. As can be seen, this module is not affected by the shadow cast by other trackers.

Table I. Relative distance (in $\mathrm{m}$ ) between the different reference modules.

\begin{tabular}{lrrrrrrrrr}
\hline Reference modules & 1 & \multicolumn{1}{c}{3} & \multicolumn{1}{c}{3} & \multicolumn{1}{c}{4} & 5 & 6 & 7 & 8 & 9 \\
\hline 1 & 0 & 698 & 466 & 1615 & 2438 & 2018 & 2650 & 855 & 1302 \\
2 & 0 & 0 & 744 & 2047 & 2712 & 2065 & 2716 & 1293 & 1290 \\
3 & 0 & 0 & 0 & 1310 & 2044 & 1557 & 2196 & 550 & 837 \\
4 & 0 & 0 & 0 & 0 & 942 & 1160 & 1517 & 772 & 1168 \\
5 & 0 & 0 & 0 & 0 & 0 & 937 & 816 & 1592 & 1509 \\
6 & 0 & 0 & 0 & 0 & 0 & 0 & 652 & 1331 & 776 \\
7 & 0 & 0 & 0 & 0 & 0 & 0 & 0 & 1906 & 1428 \\
8 & 0 & 0 & 0 & 0 & 0 & 0 & 0 & 0 & 835 \\
\hline
\end{tabular}

Bold data remark the maximum separation.

avoid any bias derived from possible calibration errors, soiling differences and so on. Even at a sunny instant around midday, the temperature of the different modules of the PV plant is not necessarily the same. That is why no correction was made in calibration values of the reference modules for the temperature measurement. According to the calibration report of the reference modules, the estimated error of the temperature measurements is $\pm 2 \mathrm{~K}$. Horizontal irradiance, $G_{0}$, and wind speed, $V_{\mathrm{w}}$, were also measured at a meteorological station located within the PV plant. Solar radiation, temperature and wind speed values were recorded in a database as 10 -min mean values.

Similar measurements were also taken in two reference modules at another PV plant located in Tudela (northern Spain). In this case, the two modules used to measure the irradiance and temperature were only $30 \mathrm{~m}$ apart.

\section{SOLAR IRRADIATION DISPERSION}

\subsection{In daily terms}

Daily irradiation values exert a considerable influence on PV engineering practices. For example, the condition of
PV plants is often analysed in terms of daily energy/irradiation ratios. As a result, particular attention is paid here to daily irradiation dispersion. Figure 3 shows the daily irradiation differences, $\Delta G_{\mathrm{d}}$, recorded at the nine points of Amareleja on the same days as Figure 1. Each day, the largest irradiation value is taken as a baseline and the differences are in relation to this baseline.

As expected from time integration, dispersion in irradiation is lower than dispersion in irradiance. However, it is still very significant. Figure 4 presents the histogram of the maximum daily irradiation difference (among the 36 possible combinations of two reference modules at Amareleja), $\Delta G_{\mathrm{d}, \mathrm{MAX}}$. On more than one-third of the days, this difference is greater than $5 \%$.

\subsection{Correlation with clearness index and distance}

Because irradiation dispersion is due to different cloud cover, correlation with clearness index (defined as the ratio of the horizontal global irradiation to the corresponding extraterrestrial irradiation) and distance from observation points can be suspected. Certain correlation with daily clearness index, $K_{\mathrm{Td}}$, is observed in Figure 5 , where $\Delta G_{\mathrm{d}}$, 


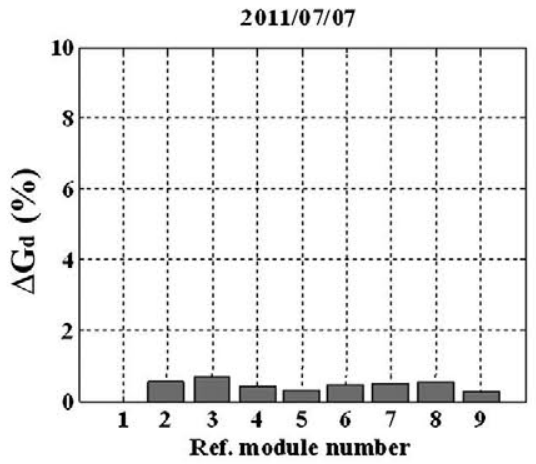

a)

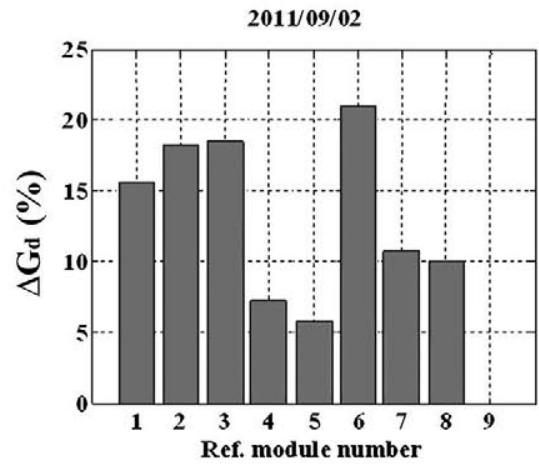

b)

Figure 3. Differences between the daily irradiation measured for each reference module and the highest irradiation value (expressed as a \%): (a) Clear day $\left(G_{\mathrm{d}}=11774 \mathrm{Wh} / \mathrm{m}^{2}\right)$, (b) partially cloudy day $\left(G_{\mathrm{d}}=7985 \mathrm{Wh} / \mathrm{m}^{2}\right)$.

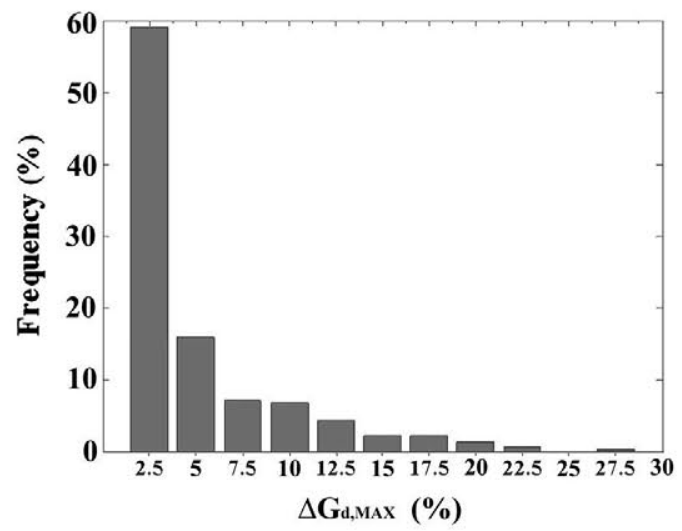

Figure 4. Histogram of the maximum daily irradiation differences measured over the course of the study year in Amareleja photovoltaic plant. Abscissa tick labels indicate the centre of each bin.

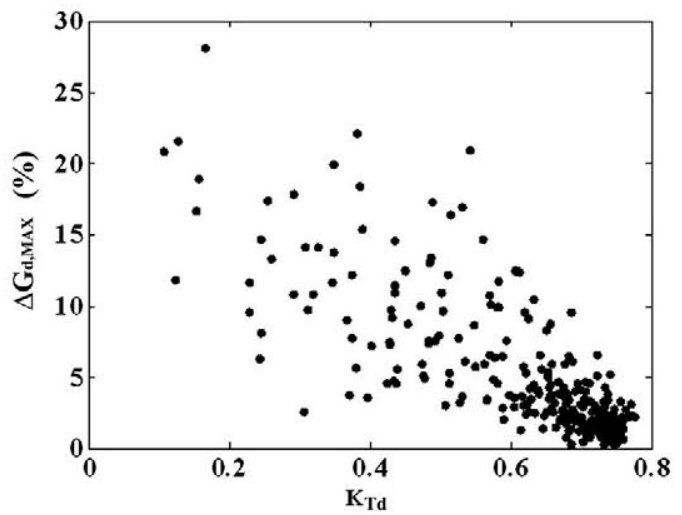

Figure 5. Maximum differences between the daily irradiation measured by the different reference modules over the course of the study year compared to the daily clearness index.

MAX values are plotted against $K_{\mathrm{Td}}$. The greater the $K_{\mathrm{Td}}$, the lower the $\Delta G_{\mathrm{d}, \mathrm{MAX}}$. One can suppose, hence, a linear correlation between them, but the $R^{2}$ value obtained for the linear regression is poor $\left(R^{2}<0.65\right)$. Dependence with distance can be clearly observed when considering very short versus relatively large distances. Figure 6 shows, again for all the days of the year and against $K_{\mathrm{Td}}$, the irradiation differences observed at $30 \mathrm{~m}$ (the two Tudela sensors) and at $466 \mathrm{~m}$ (the two nearest Amareleja sensors). As expected, the greater the distance, the greater the irradiation differences, with corresponding maximum differences of $2 \%$ and $18 \%$. However, and somewhat surprisingly, such dependence does not appear when considering differences between relatively large distances (distances of more than several hundred metres). Figure 7 presents the irradiation differences at 466 and $2716 \mathrm{~m}$ (the two Amareleja sensors that are the closest together and the two that are the furthest apart). Now, irradiation differences are very similar. This lack of correlation, between irradiation dispersion and distance, can be understood as being coherent with the somewhat chaotic cloud behaviour and observation distances in the order of the relevant cloud size, around some hundred metres. Whichever the case, observations of dispersion in solar radiation at distances ranging from 50 to $400 \mathrm{~m}$ would be welcome.

No correlation between irradiation dispersion and wind speed was found.

\subsection{In hourly, monthly and yearly terms}

As expected, the observed irradiation dispersion decreases with increasing integration period. Figure 8 shows the histogram of the maximum hourly irradiation differences, $\Delta G_{\mathrm{h}, \mathrm{MAX}}$, recorded at Amareleja. $\Delta G_{\mathrm{h}, \mathrm{MAX}}$ values higher than $10 \%$ can be observed for more than one-third of the hours. Figure 9 represents the maximum monthly irradiation differences, $\Delta G_{\mathrm{m}, \mathrm{MAx}}$, for all the months plotted against the monthly clearness index, $K_{\mathrm{Tm}}$, showing some kind of correlation between them. One can suppose, again, a linear correlation, but the uncertainty in the regression parameters is high $\left(R^{2}<0.75\right)$. Moreover, there are no data for $K_{\mathrm{Tm}}$ values below 0.4 , but it is not clear at all that $\Delta G_{\mathrm{m}}$, MAX is a maximum when the clearness index is zero. Figure 9 does show that monthly irradiation differences 


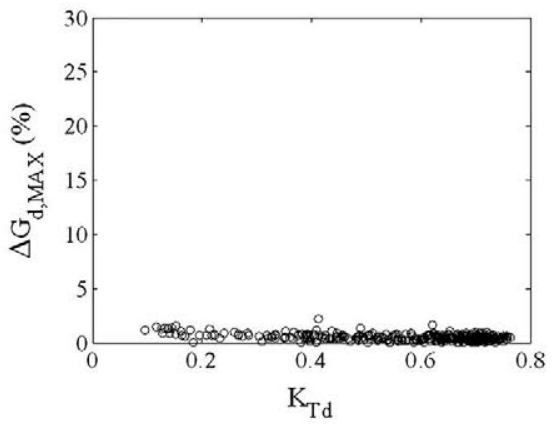

a)

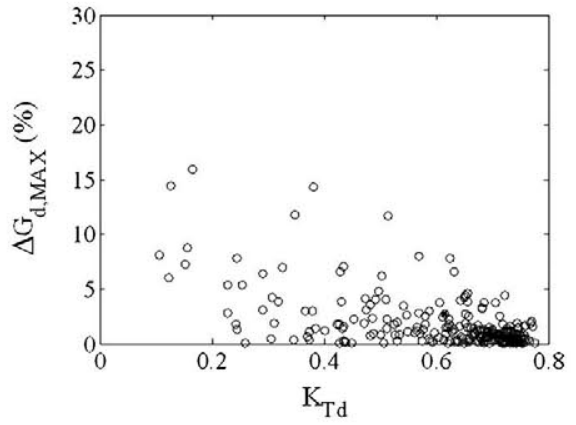

b)

Figure 6. Differences between the daily irradiation measured by two reference modules in the course of the year studied compared to the daily clearness index: (a) the two reference modules $30 \mathrm{~m}$ apart at the PV plant in Tudela, (b) reference modules 1 and 3 at the Amareleja PV plant $(466 \mathrm{~m}$ apart).

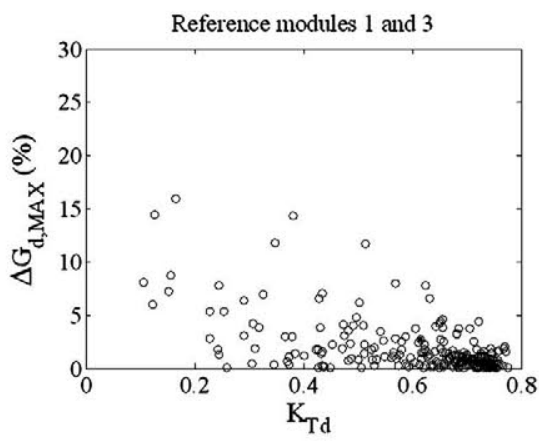

a)

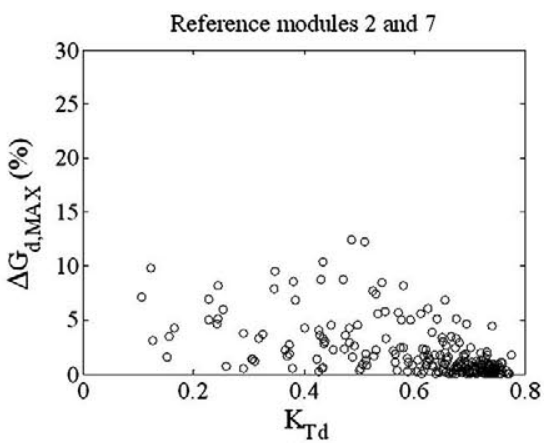

b)

Figure 7. Differences between the daily irradiation measured by two reference modules in the course of the year studied compared to the daily clearness index: (a) modules 1 and 3 (466 m apart); (b) modules 2 and 7 (2716 $\mathrm{m}$ apart).

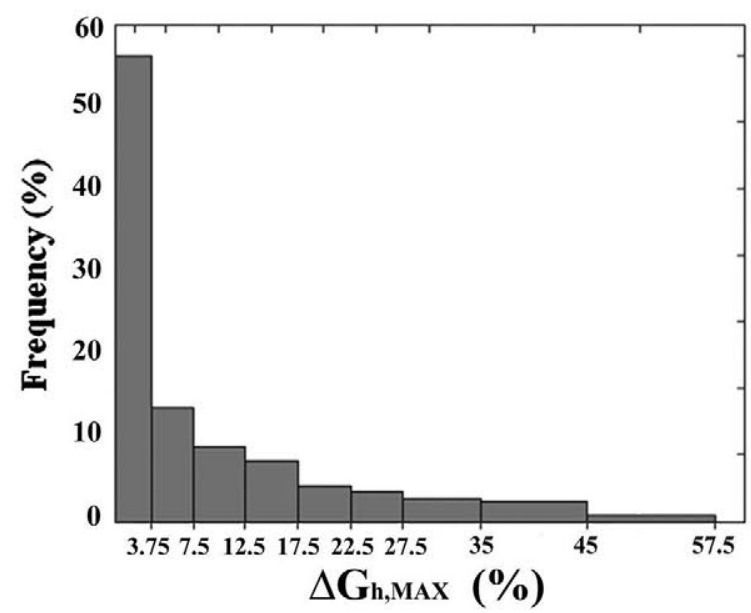

Figure 8. Histogram of the maximum hourly irradiation differences measured in the course of the study year. Abscissa tick labels indicate the limits of the bins.

remain below $5 \%$. Those values of $\Delta G_{\mathrm{m}, \mathrm{MAx}}$ are included in Table II together with the maximum values of $\Delta G_{\mathrm{d}, \mathrm{MAX}}$ for each month, $\operatorname{Max}\left(\Delta G_{\mathrm{d}, \mathrm{MAX}}\right)_{\mathrm{m}}$. The $a$ parameter has

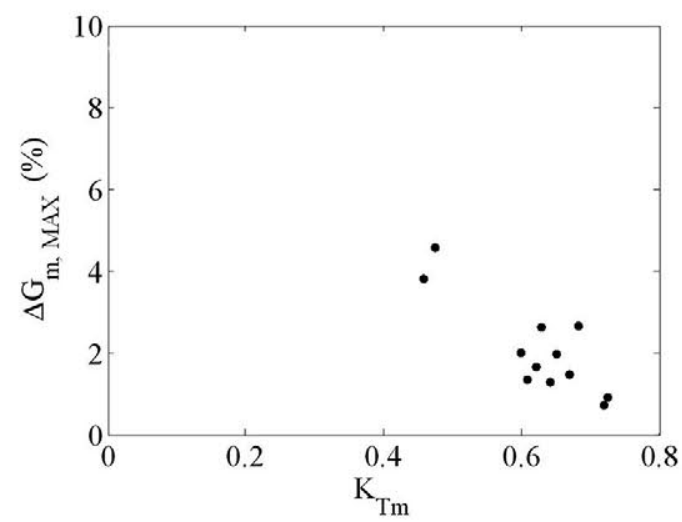

Figure 9. Maximum differences between the monthly irradiation values recorded by the nine reference modules for each of the months of the year under study.

been obtained by fitting the relation between the irradiation dispersion and the integration period to a geometric function as follows:

$$
\Delta G_{\mathrm{m}, \mathrm{MAX}}=\operatorname{Max}\left(\Delta G_{\mathrm{d}, \mathrm{MAX}}\right)_{\mathrm{m}} \cdot N^{-a}
$$


Table II. Maximum values of $\Delta G_{\mathrm{d}, \mathrm{MAX}}$ and maximum monthly irradiation differences, $\Delta G_{\mathrm{m}, \mathrm{MAX}}$, for each month of the study year (in \%).

\begin{tabular}{lcccccccccccccc}
\hline & Jul & Aug & Sep & Oct & Nov & Dec & Jan & Feb & Mar & Apr & May & Jun \\
\hline Max $\left(\triangle G_{\mathrm{d}, \mathrm{MAX}}\right)_{\mathrm{m}}$ & 4.1 & 18.4 & 20.9 & 12.4 & 28.1 & 18.1 & 13.8 & 8.3 & 18.9 & 17.8 & 14.2 & 10.9 \\
$\Delta G_{\mathrm{m}, \mathrm{MAX}}$ & 0.92 & 1.28 & 2.64 & 1.66 & 4.58 & 3.11 & 1.90 & 0.75 & 1.37 & 3.84 & 2.01 & 2.66 \\
$a$ & 0.44 & 0.78 & 0.61 & 0.59 & 0.53 & 0.52 & 0.58 & 0.71 & 0.77 & 0.45 & 0.57 & 0.42 \\
a (mean) & & & & & & $0.58=1 / 2$ & & & \\
\hline
\end{tabular}

$a$ is the parameter that best fits Equation 1 for each pair $M a x\left(\Delta G_{d, M A x}\right)_{m}$ and $\Delta G_{m, M A X}$.

where $N$ is the number of days of the integration period $(N=30)$. The value for $a$ is near 0.5 for every month, which means that maximum irradiation differences are reduced by a factor of $\approx 1 / \sqrt{30}$ when the integration period increases from 1 day to 1 month. This law $(1 / \sqrt{N})$ means that there is no correlation among deviations in irradiation observed on different days. It is interesting to note that a similar law explains the smoothing of the output power fluctuations by geographical dispersion of PV systems $[10,14,15]$.

Figure 10 presents the monthly irradiation differences at 466 and $2716 \mathrm{~m}$ (the two Amareleja sensors that are closest together and furthest apart). As in the case of daily irradiation differences, no correlation with distance can be observed when considering monthly differences among such relatively large distances. Finally, differences between the yearly irradiation values, $\Delta G_{\mathrm{y}}$, recorded for each reference module, are plotted in Figure 11. Now, the irradiation differences remain below $2 \%$.

\section{MODULE TEMPERATURE DISPERSION}

It is worth remembering that the effect of the operating temperature of a PV generator on the energy it produces is far less than the effect of solar radiation. Therefore,

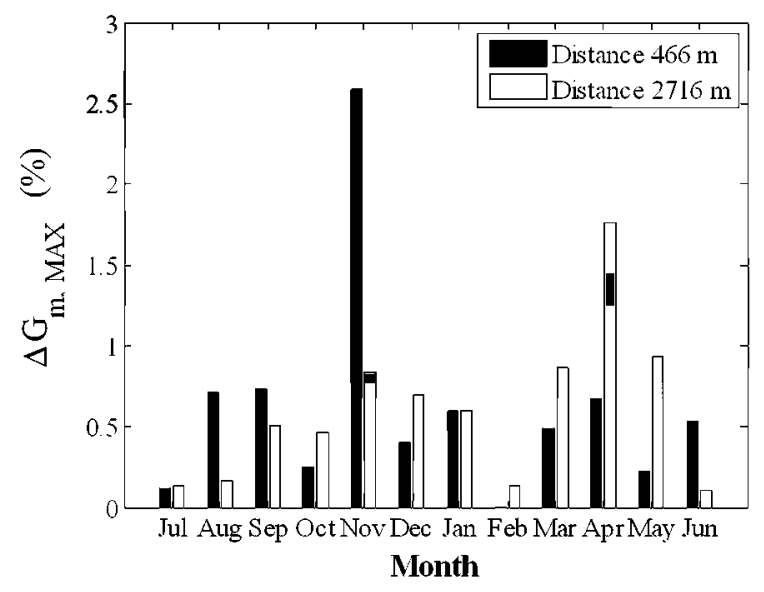

Figure 10. Maximum differences between the monthly irradiation values recorded by the two reference modules $466 \mathrm{~m}$ apart and $2716 \mathrm{~m}$ over the year under study. possible temperature errors tend to be less important than irradiation ones when evaluating the performance of a PV system. Note that temperatures shown in this paper are effective temperatures based upon $V_{\mathrm{oc}}$ measurements of reference modules. It eliminates uncertainties between a regular temperature sensor and the actual temperature of the cells in the module. To calculate the mean daily, monthly and annual temperatures, the values registered over the night time were not taken into account.

\subsection{Dispersion of the mean daily temperature}

The maximum differences found between the mean daily temperatures of the reference modules, $\Delta T_{\mathrm{Cd}, \mathrm{MAX}}$, are around $7 \mathrm{~K}$. No correlation between the mean wind speed and the maximum differences in the daily mean temperature was observed. It is worth noting that all the temperatures indicated herein are recorded at an equal point on different trackers. It is likely that temperature differences between different points of the same tracker (for example, between upper and lower corners) are also significant. However, this paper reports only on temperature differences due to geographical dispersion. Observations on temperature differences within the same tracker are left for future work.

\subsection{Dispersion in the mean monthly and annual temperature}

The maximum differences measured between the mean monthly temperature values were similar for all the months of the year of study, all being less than $3 \mathrm{~K}$. The maximum difference in the mean annual temperature recorded in the nine modules was approximately $2 \mathrm{~K}$. Those differences are not significant in relation to the estimated measurement error.

\subsection{Dispersion of temperature in relation to distance}

Neither does the difference between the mean temperatures recorded in two different modules at the plant appear to be directly related to the distance between them. To see what happens in the case of modules that are much closer together than those studied at the Amareleja PV plant, the differences recorded in the course of the year in the mean 


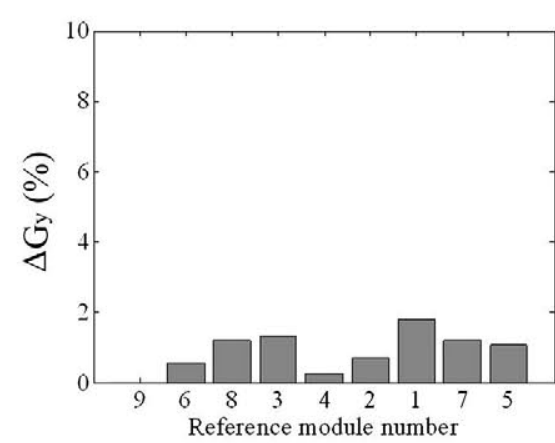

a)

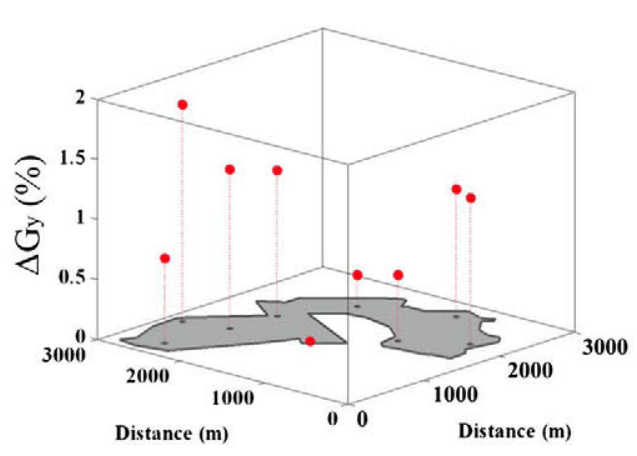

b)

Figure 11. Differences between the annual irradiation recorded by each reference module and the highest irradiation value (\%): (a) reference modules sorted in ascending order, according to the distance from the module in which the highest annual irradiation value was recorded: (b) reference module located at its actual position within the plant.

daily temperature in the modules from the Tudela PV plant were also analysed, bearing in mind that these modules are just $30 \mathrm{~m}$ apart. The dispersion values found were very similar to those measured at the Amareleja PV plant. Therefore, the dispersion in the mean temperature of the different modules appears to be clearly independent of the distance apart.

\section{AVERAGing SEVERAL SENSORS}

As is evident from the previous paragraphs, in order to ensure that the values measured are representative of the operating conditions across the entire surface area of the PV plant, it is extremely important to determine the number of irradiation and temperature sensors to be used and their spatial distribution.

To quantify the dispersion in irradiation measurements, hereinafter, we refer to $F_{\triangle \mathrm{Gp} 5}$ as the fraction (in \%) of deviations greater than $5 \%$ in the irradiation calculated over an integration period $p$ (for example, 1 hour, 1 day and 1 month), throughout the whole year. As an example, we term $F_{\Delta \mathrm{Gh} 5}$ as the fraction of maximum deviations greater than $5 \%$ in hourly irradiation throughout the year. As shown previously, $F_{\Delta \mathrm{Gh} 5}$ is near $40 \%$, which means that working on an hourly basis, the use of a single sensor to measure the irradiation at points that are more than $450 \mathrm{~m}$ apart from that sensor can lead to an error that is greater than $5 \%$ in nearly $40 \%$ of the values obtained for the whole year. A similar value is obtained by working on a daily ba$\operatorname{sis}\left(F_{\Delta \mathrm{Gd} 5}=30 \%\right)$.

The most obvious way to reduce dispersion is by using the average of measurements of several sensors distributed across the entire area. In order to analyse the effect of averaging irradiation measurements, the nine available sensors in Amareleja PV plant were divided into several groups of the same number of elements (starting from a single sensor up to four sensors per group). Each group were made up of those sensors located closest to each other. Table III summarises the groups of sensors considered for the analysis.

Figure 12a shows the histograms of the maximum daily irradiation differences measured among those groups of sensors included in Table III, over the course of the study year. Each histogram corresponds to a different number of sensors per group. The value of $F_{\Delta \mathrm{Gd} 5}$ considerably decreases by increasing the number of sensors per group from one to three, which is in accordance with chaotic cloud behaviour. However, dispersion between groups of three and four sensors is already pretty similar. Figure $12 \mathrm{~b}$ shows the maximum differences in daily irradiation measurements, with respect to the mean value measured with the nine sensors, obtained using individual sensors or considering groups of three sensors located close to each other. The $F_{\Delta \mathrm{Gd} 5}$ factor decreases from $24.7 \%$ (individual sensors) to $4.7 \%$ (groups of three sensors). Similar results were obtained for groups of three sensors located farther apart from each other. Therefore, for flat-ground PV plants larger than a few hectares, the precise location of sensors appears not to be very important if the separation among them is around $450 \mathrm{~m}$ or more. Again, observations regarding dispersion for separations ranging from 50 to $400 \mathrm{~m}$ would be welcome.

A similar analysis can be made about the reduction of dispersion in module temperature measurements by using the average of several sensors. To quantify the dispersion in daily mean module temperature measurements, we refer to $F_{\Delta \mathrm{Tcd} 2}$ as the fraction (in $\%$ ) of deviations larger than

Table III. Groups of sensors considered for the analysis.

\begin{tabular}{ll} 
Number of sensors per group & Sensors' reference numbers \\
\hline 1 (single sensors) & $1,2,3,4,5,6,7,8,9$ \\
2 (pairs) & $1-2,1-3,2-3,3-8,8-4,9-6,6-7$ \\
3 (groups of three) & $1-2-3,5-6-7,3-8-9,1-3-8$ \\
4 (groups of four) & $1-2-3-8,2-3-8-9,8-9-6-4,6-4-$ \\
& $5-7$ \\
\hline
\end{tabular}

The reference numbers of the sensors that comprise each group are those shown in Figure 2 . 


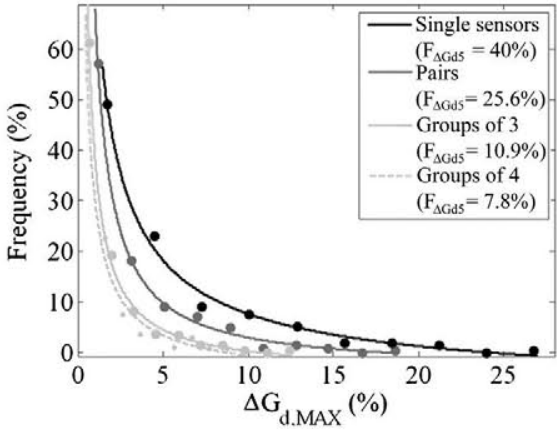

a)

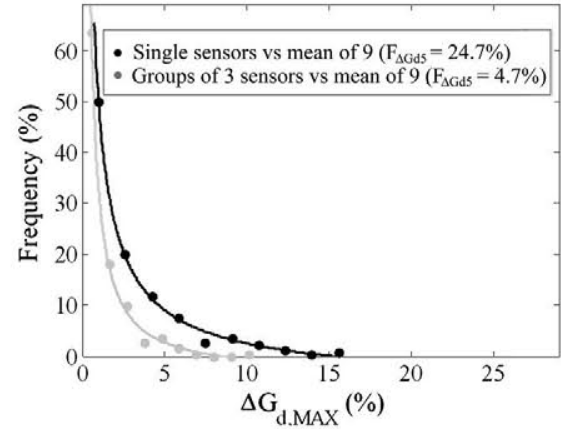

b)

Figure 12. (a) Histograms of the maximum daily irradiation differences measured among different groups of sensors over the course of the study year; (b) histograms of the maximum daily irradiation differences measured with regard to the mean value obtained with the nine sensors.

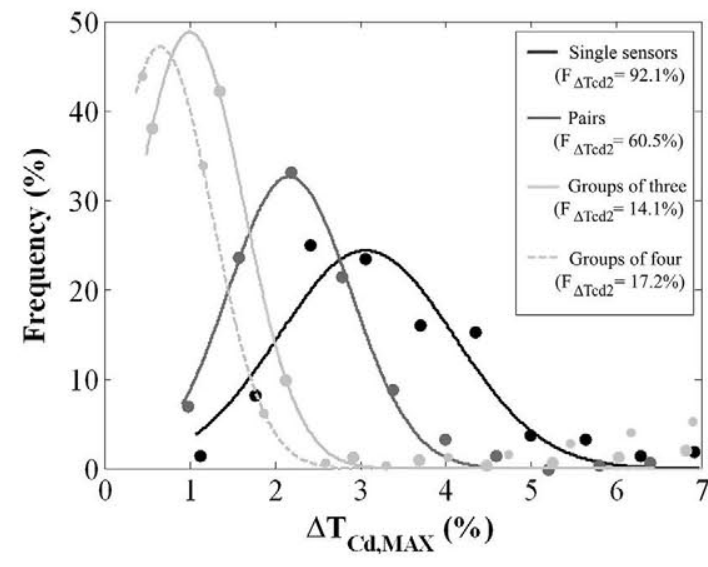

Figure 13. Histograms of the maximum daily mean module temperature differences measured among different groups of sensors over the course of the study year.

$2 \mathrm{~K}$ in such temperatures, throughout the whole year. Figure 13 shows the histograms of the maximum daily mean module temperature differences measured, over the course of the study year, among the same groups of sensors considered in Figure 12a. Each histogram corresponds to a different number of sensors per group.

As in the case of solar irradiation dispersion, the value of $F_{\triangle \mathrm{Tcd} 2}$ considerably decreases by increasing the number of sensors per group from one to three and becomes similar between groups of three and four sensors.

\section{CONCLUSIONS}

\subsection{Solar irradiation dispersion}

Geographical dispersion in hourly and daily irradiation measurements at a large PV plant can be significantly larger than is commonly supposed. Differences of almost $20 \%$ in daily irradiation values and greater than $40 \%$ in hourly irradiation values were recorded between points positioned 450-2700 m apart at a $250 \mathrm{Ha}$ PV plant located in Amareleja (Portugal). The magnitude of the deviations in the daily irradiation is clearly related to the daily clearness index, being under $5 \%$ for most of the clear days $\left(K_{\mathrm{Td}}\right.$ 0.7 ) of the year studied and increasing as $K_{\mathrm{Td}}$ decreases. There is no clear relationship between deviations in the hourly irradiation and the daily clearness index. Indeed, deviations of more than $40 \%$ were found in days with $K_{\mathrm{Td}}>0.7$.

Monthly and yearly irradiation values are far more uniform across the whole PV plant. Maximum deviations were around $2 \%$ for yearly irradiation and under $4 \%$ for monthly irradiation.

Deviations are independent of distance if the measurement points are spaced $450 \mathrm{~m}$ or more apart. For points less than $30 \mathrm{~m}$ apart, all the irradiation measurements typically differ by less than $2 \%$. From the available data, no observations can be made about distances between 30 and $450 \mathrm{~m}$. For this reason, observations regarding dispersion in solar radiation within that range of distances would be welcome.

In order to reduce the uncertainty introduced by the geographical dispersion of the operating conditions, it is advisable for large PV plants to install several irradiance sensors across the whole area occupied by the generator. Let us say that for flat-ground PV plants larger than a few hectares, three correctly distributed sensors seem to be sufficient. Account should be taken of the fact that, in such PV plants, the use of sensors at a distance of less than $30 \mathrm{~m}$ apart only provides redundant measurements because the geographical dispersion of irradiation has no measurable impact for such a short distance.

\subsection{Module temperature dispersion}

Maximum differences of 6-7 K were found between the daily mean temperatures of PV modules 450-2700 m apart in the Amareleja PV plant. The same differences were found in two modules just $30 \mathrm{~m}$ apart, located at another PV plant. Thus, it is clear that geographical dispersion in 
temperature values is independent of distance. Monthly and yearly mean temperature deviations were only around $2 \mathrm{~K}$, which are not significant in relation to the estimated measurement error. It was also possible to show that there is no relationship between dispersion in daily temperature and daily mean wind speed.

The number and location of temperature sensors are not as important as the number and location of irradiation sensors. Nevertheless, it seems advisable to position the same number of temperature sensors as irradiance sensors distributed throughout the entire area. Calibrated modules can even be used to measure both irradiance and module temperature at the same time.

\section{ACKNOWLEDGEMENTS}

This work has been partially financed by the Seventh Framework Programme of the European Commission with the project PVCROPS (Photovoltaic Cost R€duction, Reliability, Operational Performance, Prediction and Simulation - Grant Agreement no: 308468).

\section{REFERENCES}

1. Reich NH, Mueller B, Armbruster A, van Sark WGJHM, Kiefer K, Reise C. Performance ratio revisited: is $\mathrm{PR}>90 \%$ realistic? Progress in Photovoltaics: Research and Applications 2012; 20(6): 717-26. DOI: $10.1002 /$ pip. 1219

2. Franghiadakis Y, Tzanetakis P. Explicit empirical relation for the monthly average cell-temperature performance ratio of photovoltaic arrays. Progress in Photovoltaics: Research and Applications 2006; 14(6): 541-51. DOI: 10.1002/pip.680

3. Kuszmaul S, Ellis A, Stein J, Johnson L. Lanai highdensity irradiance sensor network for characterizing solar resource variability of MW-scale PV system, 35th IEEE Photovoltaic Specialists Conference, Honolulu 2010.

4. Zehner M, Hartmann M, Weizenbeck J, Gratzl T, Weig1 T, Mayer B, Wirth G, Krawczynski M, Betts T, Gottschalg R, Hammer A, Giesler B, Becker G, Mayer O. Systematic analysis of meteorological irradiation effects. 25th European Photovoltaic Solar Energy Conference and Exhibition /5th World Conference on Photovoltaic Energy Conversion, 6-10 September 2010, Valencia, Spain.
5. Zehner M, Weigl T, Hartmann M, Thaler S, Schrank O, Czakalla M, Mayer B, Betts T, Gottschalg R, Behrens K, Langlo G, Giesler B, Becker G, Mayer O Energy loss due to irradiance enhancement. 26th European Photovoltaic Solar Energy Conference and Exhibition, September 2011, Hamburg, Germany.

6. Weigl T, Nagl L, Weizenbeck J, Zehner M, Augel M, Öchsner P, Giesler B, Becker G, Mayer O, Betts T, Gottschalg R Modelling and validation of spatial irradiance characteristics for localized irradiance fluctuations and enhancements. 27th European Photovoltaic Solar Energy Conference and Exhibition, September 2012, Frankfurt, Germany.

7. Renné D. NREL data set shows clouds' effects on solar power, NREL News Release No. 4411, 31/08/11

8. Marcos J, Marroyo L, Lorenzo E, Alvira D, Izco E. Power output fluctuations in large scale PV plants: one year observations with one second resolution and a derived analytic model. Progress in Photovoltaics: Research and Applications 2011; 19(2): 218-227. DOI: $10.1002 /$ pip. 1016

9. Yordanov G, Midtg ${ }^{\circ}$ ard $O$, Saetre T, Nielsen H, Norum L. Overirradiance (cloud enhancement) events at high latitudes. IEEE Journal of Photovoltaics 2013; 3(1): 271-277.

10. Marcos J, Marroyo L, Lorenzo E, García M. Smoothing of PV power fluctuations by geographical dispersion. Progress in Photovoltaics: Research and Applications 2011; 20: 2. DOI: 10.1002/pip.1127

11. Bucher C, Betcke J, Andersson G, Bletterie B, Küng L. Simulation of distribution grids with photovoltaics by means of stochastic load profiles and irradiance data. 27th European Photovoltaic Solar Energy Conference and Exhibition, September 2012, Frankfurt, Germany.

12. Martinez-Moreno F, Lorenzo E, Muñoz J, Moretón R. On the testing of large PV arrays. Progress in Photovoltaics: Research and Applications 2011; 19: 3. DOI: $10.1002 /$ pip. 1102

13. IEC 60891: 2009 Ed 2, Procedures for temperature and irradiance corrections to measured $\mathrm{I}-\mathrm{V}$ characteristics of crystalline silicon photovoltaic (PV) devices.

14. Murata A, Yamaguchi H, Otani K. A method of estimating the output fluctuation of many photovoltaic power generation systems dispersed in a wide area. Electrical Engineering in Japan 2009; 166(4): 9-19.

15. Hoff TE, Perez R. Quantifying PV power output variability. Solar Energy 2010; 84: 1782-1793. 